\section{Case Reports in Dermatology}

Case Rep Dermatol 2018;10:257-262

DOI: 10.1159/000495020

Published online: November 28, 2018

(C) 2018 The Author(s)

Published by S. Karger AG, Base

www.karger.com/cde

This article is licensed under the Creative Commons Attribution-NonCommercialNoDerivatives 4.0 International License (CC BY-NC-ND) (http://www.karger.com/Services/ OpenAccessLicense). Usage and distribution for commercial purposes as well as any distribution of modified material requires written permission.

\title{
Keloid Formation due to Repetitive Mammographies
}

\author{
Tim Pruimboom ${ }^{a}$ b Marc R. Scheltinga ${ }^{b}$ \\ ${ }^{a}$ Faculty of Health, Medicine and Life Sciences, Maastricht University, \\ Maastricht, The Netherlands; 'bepartment of General Surgery, Máxima Medical Center, \\ Veldhoven, The Netherlands
}

\section{Keywords}

Keloid · Scars · Chest · Adult · Compression · Mammography

\begin{abstract}
A keloid is the result of an abnormal wound healing response to a variety of skin injuries, characterized by a well-circumscribed, firm, irregular, mildly tender, and pink to purple hyperpigmented lump with a glossy surface. The present case reports on excessive formation of keloid due to repetitive mammographies causing symptomatic, cosmetically disturbing symptoms.

\section{Introduction}

Keloid scars were first described in the Edwin Smith Papyrus, dating back to 1700 BCE [1]. The African Yoruba tribe reported on keloids in the 10th century, followed by Retz in 1790 referring to keloid as "dartre de graisse" or "fatty hernias" [2]. Alibert coined the term keloid in 1817. The term is derived from the word cheloide, meaning "like a crab's claw," referring to the claw like extension of the lesions and a tendency to grow in a lateral direction [3].

Keloid scarring is an abnormal wound response that does not regress spontaneously. It is defined as an overgrowth of dense, fibrous tissue following healing in a variety of types of skin injuries extending beyond the borders of the original cutaneous insult and invading adjacent 
normal dermis [4]. Keloids mostly affect, but are not limited to, younger patients with higher Fitzpatrick skin phototypes [5]. Keloid scars tend to develop more readily during and after puberty, and disproportionately affect African American, Latin American, and Asian populations with a prevalence ranging from 0.3 to $16 \%$ [6].

On inspection, keloids are characterized by a well-circumscribed, firm, irregular, mildly tender, and pink-purple lumps usually accompanied by hyperpigmentation, and a glossy surface with occasional telangiectasias [7]. They are often asymptomatic but may be pruritic or painful. Furthermore, keloids may grow to gigantic sizes disturbing the patient's quality of life [8]. Despite the availability of numerous treatments, there is no consensus on the most effective option. Although keloid formation mostly results from abnormal wound healing in response to skin trauma or inflammation, this case reports on comprehensive keloid scars following a series of mammographies, causing significant cosmetic, symptomatic, as well as therapeutic problems.

\section{Case Report}

In August 1993, a then 45-year-old Indonesian female underwent a modified radical left mastectomy for T1N0M0 breast cancer. Her earlier history revealed keloid formation on shoulders and upper back, although she then denied significant previous traumas. Postoperatively, timed mammographies of the right breast were proposed according to the Guideline on Breast Cancer [9]. Approximately 1 month following the first mammography in November 1993, keloid tissue started to emerge around the nonoperated right breast, reflecting the position of the rigid breast compression paddle that was used for the mammography. Although she was worried that the lesions would progress, mammography screening was continued annually, indeed leading to worsening of the keloid formation.

When she presented to our outpatient clinic in 2005, a physical examination revealed firm, hyperpigmented, smooth-surfaced lesions on both sides of the thorax (Fig. 1A). Remarkably, the scars following the mastectomy remained within the confines of the original surgical incision and had not expanded over time. Conversely, keloid formation on the right side was progressive reflecting the repetitive trauma associated with approximately 12 consecutive mammographies over a period of 12 years. As she was convinced of an association between the keloid formation and the mammographies, it was decided to abandon these radiographies. She declined serial MRIs. As a consequence, it was decided to limit oncological control to palpation.

Because of the patient's progressive emotional burden associated with the growing keloids she was referred to a dermatologist who advised calendula, Dermatix ${ }^{\circledR}$ silicone gel, and corticosteroid injections, but to no avail. She was advised to seek consultation of a plastic surgeon, but she dismissed this option because of fear for invasive therapy as well as doubts on the success rates of therapies.

In 2018, she again visited our surgical department outpatient clinic as keloids had progressed even more over time. On inspection, strands of keloid tissue expanded from the right breast to the left breast causing spontaneous pain (Fig. 1B). She told us that the localizations of keloid on both her shoulders had possibly developed after insect bites and scathing, at the age of 13 years. At the age of 21, she underwent excision of these shoulder keloids. Unfortunately, widespread recurrence occurred thereafter (Fig. 2). Prior to the modified radical left mastectomy, no screening mammography has been performed. Only one diagnostic mammography has been performed 2 weeks prior to the operation without origination of keloid. Later, 
at the age of 63, a vestibular schwannoma was removed via a retroauricular incision (Fig. 3). Her sister and one daughter were also affected by excessive keloid formation following skin injuries (e.g., abrasion, surgical excision). Her other daughter, son, mother, and father were not affected.

\section{Discussion}

To the best of our knowledge, this is the first case report on formation of excessive chest keloid due to the microtraumas of repetitive mammographies. Keloid is a fibroproliferative disorder that results from an abnormal wound healing response, following a wide variety of types of skin injuries including surgery, piercings, lacerations, abrasions, tattooing, injections (e.g., vaccinations), insect bites, burns, and skin inflammation (e.g., chicken pox, acne, folliculitis), even seemingly spontaneous in the absence of any previous trauma or surgical procedure $[7,10,11]$. In the present case, it is very likely that keloid scars developed as a consequence of mammography, in the absence of additional chest traumas as reported by the patient. During mammography, breast tissue is compressed between a support table and a rigid breast compression paddle to obtain flattening of tissue with homogeneous thickness to improve visibility by spreading structures in the breast. Moreover, compression is essential for reducing total radiation dose and preventing motion artefacts. Adversely, most women experience pain and discomfort during and after this test and may even decide to avoid mammography [12]. We are also convinced that compression of soft tissue in the present case has resulted in tissue damage with subsequent keloid formation.

Normal wound healing following skin injuries is a dynamic and sophisticated process. It involves three different but overlapping time-dependent phases: inflammatory phase (2-3 days), proliferative phase (3-6 weeks), and remodelling phase (up to approximately 1 year). Most of the scar is formed by accumulated collagen produced by fibroblasts and myofibroblasts in the late proliferative phase. However, the remodelling phase is characterized by balancing collagen production and degradation and remodelling type III collagen to mature type I collagen leading to differences in scar quality.

Although the exact pathogenesis of keloid scars is incompletely understood, theories include an imbalance between production and degradation of collagen during the remodelling phase resulting in excess collagen depositions with up to 20 times greater collagen synthesis in keloid scars than in normal skin [7,11]. Moreover, mechanical force distribution is suggested to play a significant role in the pathogenesis since keloids show a preference to occur at sites as the pre-sternal skin and upper back, where tissue is exposed to mechanical forces and progress in specific shapes (e.g., butterfly, crab's claw, or dumbbell shape) due to suggested dysregulation of mechanotransduction pathways [13]. In contrast, another preferable location for keloids is the earlobe, which is not exposed to mechanical forces. Remarkably, the retroauricular incision in this case showed impressive wound healing, resulting in an almost invisible scar. Furthermore, predisposition coupled with skin injuries are factors that play a major role in keloid development [11]. Although not all patients' relatives are affected in this case, keloids have a familial tendency.

Although keloids can be asymptomatic, some lesions can cause itching, pain, or hyperesthesia. Individuals occasionally experience relief when taking a hot shower (see Patient's Perspective). A variety of treatment options were suggested aimed at reducing the size of disfiguring or crippling lesions and restoring function of the affected body part in order to improve the patient's quality of life. Unfortunately, a cure or prevention of recurrence can never be 
guaranteed $[7,10]$. One may divide the available therapies into "noninvasive medical therapies" and "surgical and other invasive therapies." The majority of noninvasive therapies are based on maintaining a balance in wound healing processes, including the reduction of fibroblast proliferation, collagen synthesis, and inflammation, in an attempt to reduce the keloid scar formation. At present, popular options are pressure garment therapy, silicone gel sheeting, intralesional corticosteroid injections, and 5-fluorouracil. Although invasive treatment modalities including surgical excision, cryotherapy, and radiotherapy are also promoted, high rates of recurrence are reported if used as a single treatment. Therefore, combinations may be more effective (e.g., cryotherapy with intralesional triamcinolone, surgical excision with 5fluorouracil) [7]. In addition, intralesional injections with a combination of triamcinolone and verapamil resulted in important scar improvement with a long-lasting result [14].

Although the presented patient previously did not opt for specialized scar treatment, she consented to an analysis by a plastic surgeon after providing treatment information, taking into account her perspective.

\section{Conclusion}

A patient developed excessive keloids following repetitive compression of breast tissue during serial mammographies. The comprehensive keloid slowly progressed over time, causing progressive pain and itching mandating a consultation of a plastic surgeon for potential treatment options.

\section{Patient's Perspective}

"Since I knew about the keloids on my shoulders, I was amazed by a rather normal wound repair after the mastectomy in 1993, leaving 'only' a hypertrophic scar. Unfortunately, the mammographies have mutilated my body. After all those years, I am used to avoiding public places such as pools and beaches. However, I will never get used to the pain and itching, particularly when it is cold. Our room temperature is standardly set at 23 degrees minimum, and I love hot showers. I used to take tramadol to reduce the pain, but that made me nauseous and tired. Currently, I only take acetaminophen twice a day for the pain. I never went to a plastic surgeon, because I was afraid of the keloid getting worse. At the moment, I would like to discuss removal of the painful scar tissue strands."

\section{Statement of Ethics}

The authors state that the patient gave her informed consent to have her case report published.

\section{Disclosure Statement}

The authors have no conflicts of interest to declare. 


\section{Case Reports in Dermatology}

\section{Author Contributions}

Both authors have been actively involved in the study and manuscript elaboration.

\section{References}

1 Breasted JH, : The Edwin Smith Surgical papyrus, Vol.1. hiero-glyphic translation and commentary. Chicago University of Chicago Press 1930:403-406.

2 Roenigk RK. Roenigk \&amp; Roenigk's Dermatologic Surgery: Principles and Practice. 2nd ed. CRC Press; 1996.

3 Alibert J. Quelques recherches sur la cheloide. Mem Soc Medicale d'Emulation; 1817.

4 Berman B, Bieley HC: Adjunct therapies to surgical management of keloids. Dermatologic surgery : official publication for American Society for Dermatologic Surgery [et al] 1996;22:126-130.

5 Forbat E, Ali FR, Al-Niaimi F. Treatment of keloid scars using light-, laser- and energy-based devices: a contemporary review of the literature. Lasers Med Sci. 2017 Dec;32(9):2145-54.

6 Austin E, Koo E, Jagdeo J: The Cellular Response of Keloids and Hypertrophic Scars to Botulinum Toxin A: A Comprehensive Literature Review. Dermatologic surgery : official publication for American Society for Dermatologic Surgery [et al] 2018;44:149-157.

7 Mari W, Alsabri SG, Tabal N, Younes S, Sherif A, Simman R. Novel Insights on Understanding of Keloid Scar: article Review. J Am Coll Clin Wound Spec. 2016 Nov;7(1-3):1-7.

8 Louw L. Keloids in rural black South Africans. Part 1: general overview and essential fatty acid hypotheses for keloid formation and prevention. Prostaglandins Leukot Essent Fatty Acids. 2000 Nov;63(5):237-45.

9 IKNL: Oncoline: Dutch Guideline on Breast Cancer. 2017

10 Jfri A, Rajeh N, Karkashan E. A Case of Multiple Spontaneous Keloid Scars. Case Rep Dermatol. 2015 Jul;7(2):156-60.

11 English RS, Shenefelt PD: Keloids and hypertrophic scars. Dermatologic surgery : official publication for American Society for Dermatologic Surgery [et al] 1999;25:631-638. https://doi.org/10.1046/j.15244725.1999.98257.x.

12 Broeders MJ, Ten Voorde M, Veldkamp WJ, van Engen RE, van Landsveld-Verhoeven C, 't Jong-Gunneman MN, et al. Comparison of a flexible versus a rigid breast compression paddle: pain experience, projected breast area, radiation dose and technical image quality. Eur Radiol. 2015 Mar;25(3):821-9.

13 Hsu CK, Lin HH, Harn HI, Hughes MW, Tang MJ, Yang CC. Mechanical forces in skin disorders. J Dermatol Sci. 2018 Jun; $90(3): 232-40$.

14 Kant SB, van den Kerckhove E, Colla C, Tuinder S, van der Hulst RR, Piatkowski de Grzymala AA. A new treatment of hypertrophic and keloid scars with combined triamcinolone and verapamil: a retrospective study. Eur J Plast Surg. 2018;41(1):69-80.
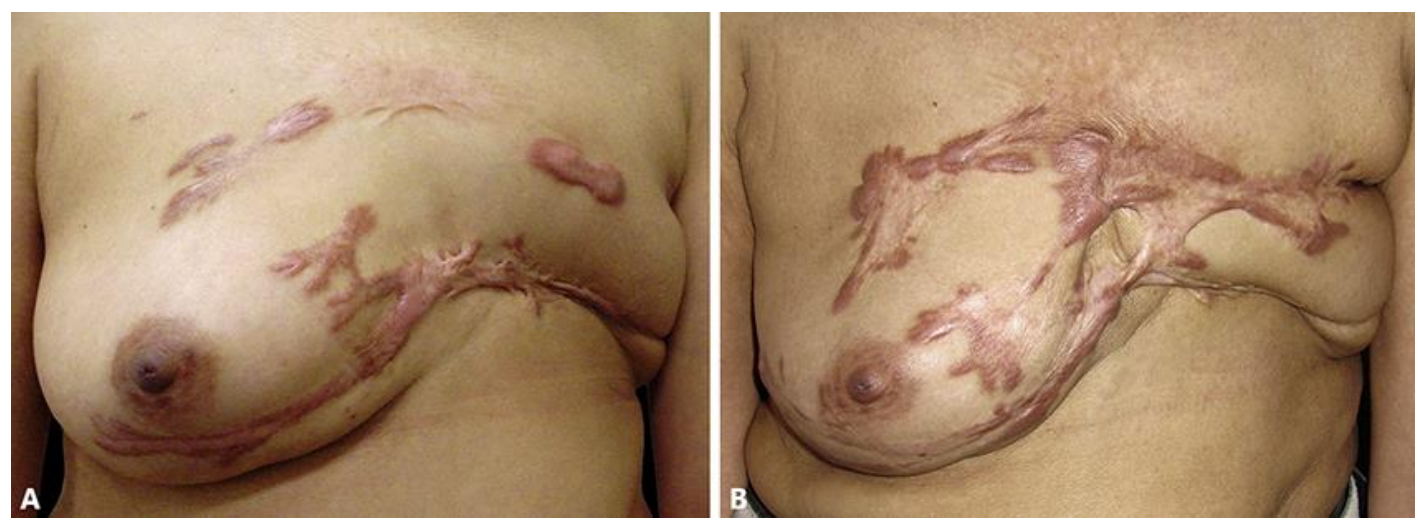

Fig. 1. Illustration of chest keloid in 2005 (A) and 2018 (B). 


\section{Case Reports in Dermatology}

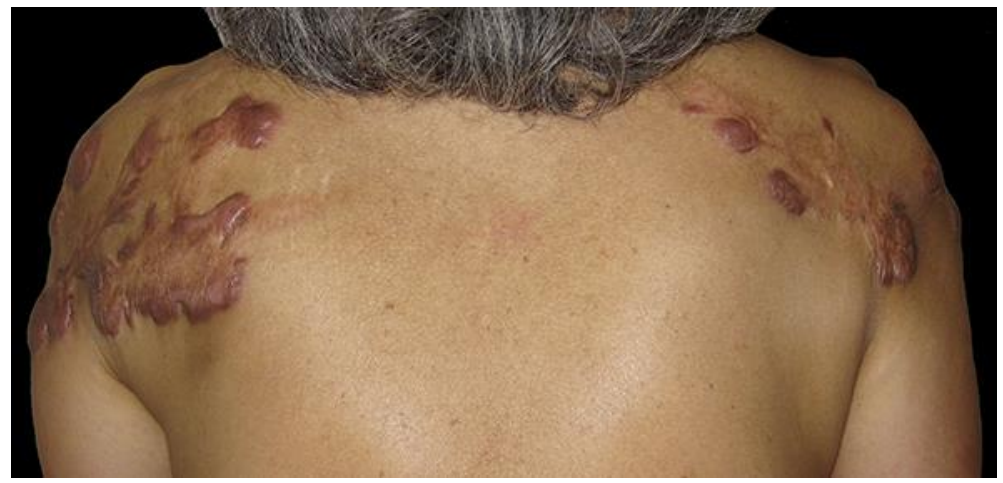

Fig. 2. Keloid on both shoulders (2018).

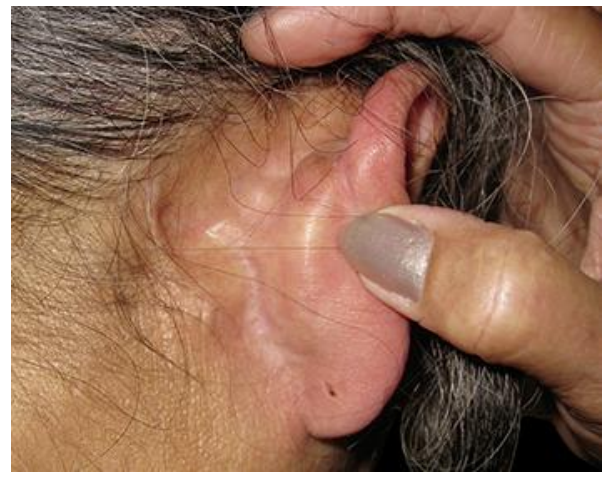

Fig. 3. Retroauricular scar (2018). 